\title{
Once-Weekly Administration of Sustained-Release Growth Hormone in Korean Prepubertal Children with Idiopathic Short Stature: A Randomized, Controlled Phase II Study
}

\author{
Jin Soon Hwang ${ }^{a}$ Hae Sang Lee ${ }^{a}$ Kee-Hyoung Lee ${ }^{b}$ Han-Wook Yoo ${ }^{c}$ \\ Dae-Yeol Lee ${ }^{d}$ Byung-Kyu Suhe Cheol Woo Ko ${ }^{f}$ Woo Yeong Chung ${ }^{g}$ \\ Dong-Kyu Jin ${ }^{\mathrm{h}}$ Choong Ho Shin ${ }^{\mathrm{i}}$ Heon-Seok Han ${ }^{j}$ Song Han $^{k}$ \\ Ho-Seong Kim'
}

${ }^{a}$ Department of Pediatrics, Ajou University School of Medicine, Suwon, Republic of Korea; ${ }^{b}$ Department of Pediatrics, College of Medicine, Korea University, Seoul, Republic of Korea; 'Asan Medical Center Children's Hospital, University of Ulsan College of Medicine, Seoul, Republic of Korea; d Department of Pediatrics, Chonbuk National University Medical School, Research Institute of Clinical Medicine, Jeonju, Republic of Korea; ${ }^{e}$ Department of Pediatrics, College of Medicine, Seoul Saint Mary's Hospital, The Catholic University of Korea, Seoul, Republic of Korea; ${ }^{f}$ Department of Pediatrics, School of Medicine, Kyungpook National University, Daegu, Republic of Korea; ${ }^{9}$ Department of Pediatrics, College of Medicine, Inje University, Busan, Republic of Korea; ${ }^{\text {h Department }}$ of Pediatrics, Sungkyunkwan University School of Medicine, Samsung Medical Center, Seoul, Republic of Korea; 'Department of Pediatrics, College of Medicine, Seoul National University, Seoul, Republic of Korea; ${ }^{\text {j}}$ Department of Pediatrics, Chungbuk National University Hospital, Chungbuk National University College of Medicine, Cheongju, Republic of Korea; ' LG Chem, Ltd., Seoul, Republic of Korea; 'Department of Pediatrics, Institute of Endocrinology, College of Medicine Yonsei University, Seoul, Republic of Korea

\section{Keywords}

Sustained-release growth hormone · Idiopathic short stature $\cdot$ Height velocity

\footnotetext{
Abstract

Background/Aims: To determine the optimal dose of LB03002, a sustained-release, once-weekly formulation of recombinant human growth hormone ( $\mathrm{rhGH})$, and to compare its efficacy and safety with daily rhGH in children with idiopathic short stature (ISS). Methods: This multicenter, randomized, open-label, phase II study included GH-naïve, prepubertal children with ISS, randomized to receive daily $\mathrm{rhGH}$ 0.37 mg/kg/week (control, $n=16$ ), LB03002 0.5 mg/kg/week
}

\begin{tabular}{ll}
\hline KARGER & ( ) 2018 The Author(s) \\
Published by S. Karger AG, Basel & Karger \\
E-Mail karger@karger.com & This article is licensed under the Creative Commons Attribution- \\
www.karger.com/hrp & $\begin{array}{l}\text { NonCommercial-NoDerivatives 4.0 International License (CC BY- } \\
\text { NC-ND) (http://www.karger.com/Services/OpenAccessLicense). } \\
\text { Usage and distribution for commercial purposes as well as any dis- } \\
\text { tribution of modified material requires written permission. }\end{array}$
\end{tabular}

( $n=14)$, or LB03002 $0.7 \mathrm{mg} / \mathrm{kg} /$ week $(n=16)$. The primary endpoint was height velocity (HV) change at week 26 . $\boldsymbol{R e}$ sults: At week 26, the least square (LS) means for HV change (cm/year) with control, LB03002 0.5 mg/kg/week, and LB03002 $0.7 \mathrm{mg} / \mathrm{kg} /$ week were 5.08, 3.65, and 4.38, and the LS means for the change in height standard deviation score were $0.65,0.49$, and 0.58 , respectively. The lower bound of the $90 \%$ confidence interval for the difference between LB03002 $0.7 \mathrm{mg} / \mathrm{kg} /$ week and the control in the LS mean for HV change (-1.72) satisfied the noninferiority margin (-1.75). Adverse events were generally mild and short-lived. Conclu-

Clinical trial registration number: ClinicalTrials.gov NCT02042170.
Ho-Seong Kim, MD

Department of Pediatrics, Institute of Endocrinology

College of Medicine Yonsei University

Seoul 03722 (Republic of Korea)

E-Mail kimho@yuhs.ac 
sion: A once-weekly regimen of LB03002 $0.7 \mathrm{mg} / \mathrm{kg}$ demonstrated noninferiority to the daily regimen of rhGH $0.37 \mathrm{mg} /$ $\mathrm{kg} /$ week in terms of HV increments. LB03002 was well tolerated and its safety profile was comparable with that of daily rhGH.

(c) 2018 The Author(s)

Published by S. Karger AG, Basel

\section{Introduction}

With the progress in molecular biotechnology, enabling large-scale production of recombinant human growth hormone (rhGH), many studies have been conducted to evaluate the use of rhGH in conditions presenting short stature but without classical growth hormone deficiency (GHD), such as chronic renal failure, Turner syndrome, Prader-Willi syndrome, small for gestational age, and idiopathic short stature (ISS). Among these, ISS is a quite frequently encountered condition as the specific causes of short stature are determined only for a small proportion (e.g., approximately 5-20\%) of children [1-3]. ISS is generally defined as the condition characterized by a height below -2.0 standard deviation score (SDS) for the corresponding age and sex, with no evidence of an underlying disorder $[4,5]$. Although the use of rhGH in children with ISS remains controversial, a number of randomized controlled studies confirmed that compared with placebo or no treatment, rhGH has a positive effect on short-term growth and final adult height in children with ISS [4, 6-11].

However, most of the available rhGH products require subcutaneous injection 6 or 7 times a week for the entire treatment period, which may reduce the treatment compliance. Thus, several technologies were used in an attempt to develop longer-acting rhGH formulations [12]. LB03002 (EutropinPlus inj.) is a once-weekly sustainedrelease formulation of rhGH manufactured using genetically modified Saccharomyces cerevisiae and contained in sodium hyaluronate microparticles suspended in medium-chain triglycerides prior to injection [13]. The efficacy and safety of LB03002 were confirmed in children and adults with GHD [14-16]. Up to date, however, there is no evidence confirming the efficacy of the once-weekly formulation in ISS patients. The aim of this study was to investigate the efficacy and safety of LB03002, and to select its optimal dose in children with ISS. As a comparator, we used Eutropin inj., the agent sharing the same expression system with LB03002 but in the immediate-release formulation (daily rhGH), approved in South Korea for the treatment of ISS, GHD, and other indications.

\section{Subjects, Materials, and Methods}

\section{Study Design and Principle}

This was a phase II, multicenter, randomized, active-controlled (daily rhGH as control), open-label, dose-finding study (between $0.5 \mathrm{mg} / \mathrm{kg} /$ week and $0.7 \mathrm{mg} / \mathrm{kg} /$ week). The lower dose was the approved dose for GHD, considered to be a comparable dose level to that of the comparator $(0.37 \mathrm{mg} / \mathrm{kg} /$ week $)$, whereas the higher dose was the maximum dose within the safety margin provided by the animal toxicity study. All the procedures were carried out according to the Declaration of Helsinki, Good Clinical Practice, and standard operating procedures of the Sponsor. The study protocol was reviewed and approved by the Ministry of Food and Drug Safety of Korea and the institutional review board of each investigational site. Patients and their parents or legal guardians were provided with a full explanation of the purpose and nature of all study procedures, and parental written informed consent was obtained before the screening. Additionally, informed consent was sought from all the patients who were able to read and write in Korean (usually $\geq 7$ years of age). The study was registered at ClinicalTrials.gov (identifier: NCT02042170).

\section{Patients}

Eligible patients were prepubertal children aged at least 4 years and diagnosed with ISS with bone ages (BA) less than 9 and 11 years for girls and boys, respectively. ISS was diagnosed whenever all of the following conditions were met: (i) height $\leq 3$ rd percentile for age and sex; (ii) normal GH secretion confirmed based on GH concentration $\geq 10 \mathrm{ng} / \mathrm{mL}$ in at least one stimulation test [17]; (iii) normal body proportion without skeletal dysplasia; and (iv) lack of pathological abnormalities that might inhibit growth. Children with GHD or other causes of short stature, including Prader-Willi syndrome, Russel-Silver syndrome, Seckel syndrome, or small for gestational age, were excluded from the study, along with the patients with some other comorbidities, such as primary hypothyroidism, adrenal insufficiency, hypogonadism, diabetes, malignancy, or closed epiphyses. In addition, children treated with sex hormones, steroids, aromatase inhibitors, thyroxine (other than administered at a stable dose for 4 weeks or more), or medications for attention deficit hyperactivity disorder were also excluded.

\section{Study Procedure}

Eligible patients were randomized to one of the three arms (daily rhGH $0.37 \mathrm{mg} / \mathrm{kg} /$ week, LB03002 $0.5 \mathrm{mg} / \mathrm{kg} /$ week, or LB03002 $0.7 \mathrm{mg} / \mathrm{kg} / \mathrm{week}$ ) in a 1:1:1 ratio with stratification according to the sex and age ( $\geq 7$ years or $<7$ years). Study visits were scheduled at the baseline, week 13 , week 26 , and week 30 . One week after the baseline visit and at week 13 , the study staff contacted the patients' parents to assure their compliance to activities set out in the consent form. Daily rhGH (control) was given 6 times per week at equally divided doses corresponding to a total weekly dose of 0.37 $\mathrm{mg} / \mathrm{kg}$, whereas the weekly rhGH (LB03002 $0.5 \mathrm{mg} / \mathrm{kg}$ or $0.7 \mathrm{mg} /$ $\mathrm{kg}$ ) was administered once a week at the dose assigned to a given group. Injections were given subcutaneously by the patients' parents or legal guardians at bedtime for 26 weeks. Injection site reactions were recorded in the diary cards. In order to assess the treatment compliance, the prescribed dose and the number of vials dispensed, used, and returned were counted and recorded at the study site. The following parameters were determined at the baseline or during the screening, at week 13 and 26: height, weight, Tanner 


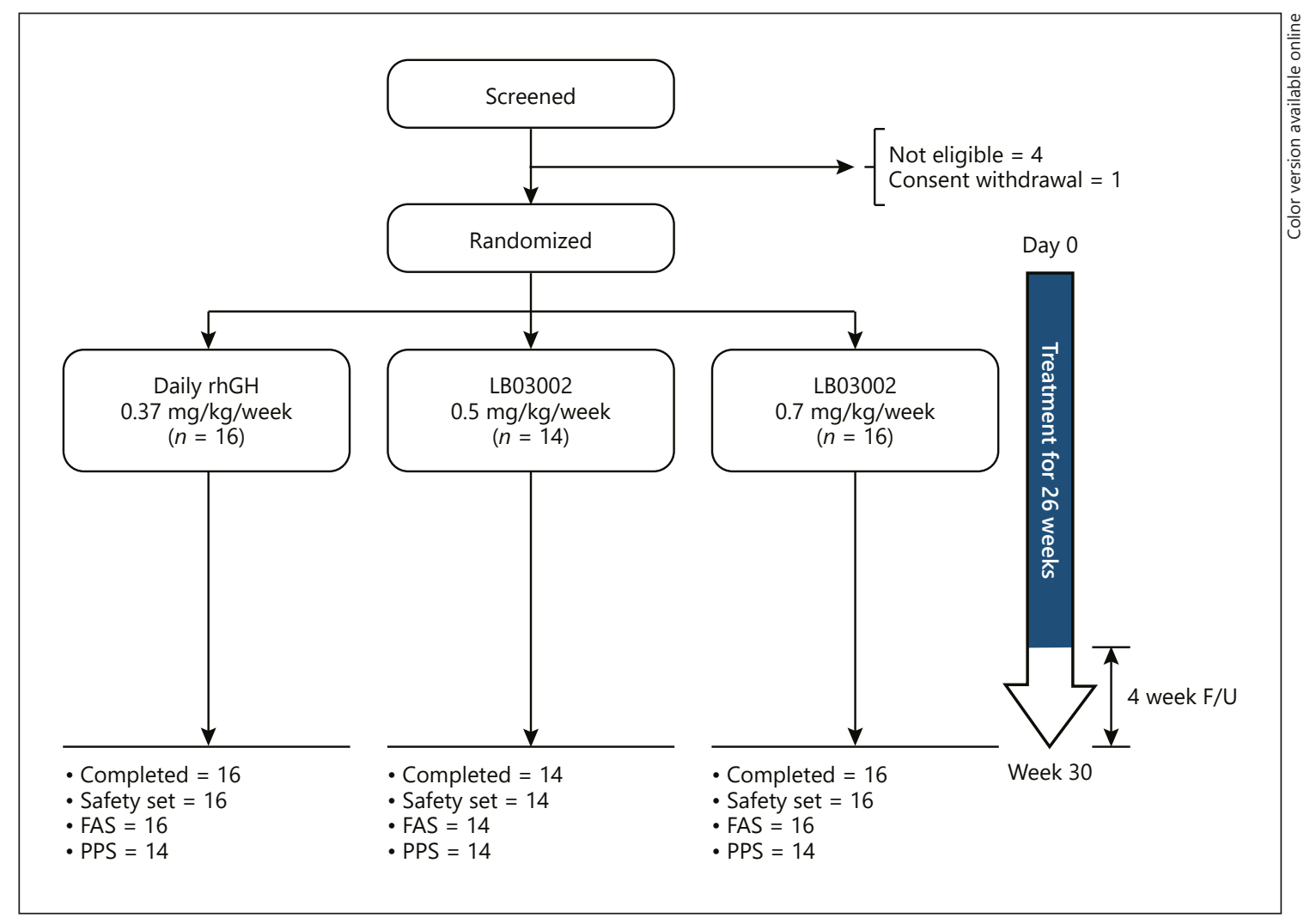

Fig. 1. Disposition of the patients. A total of 51 children with ISS were screened; 46 were randomized; and 46 completed the study. All patients were included in the analysis. After excluding 4 patients with major protocol deviations, 42 were included in the PPS, the main analysis population for efficacy evaluation.

pubertal stage, thyroid function parameters, insulin-like growth factor I (IGF-I), IGF-I-binding protein 3 (IGFBP-3), complete blood count, blood chemistry, and urinalysis. Height, weight, IGF-I, and IGFBP-3 were measured again at the follow-up visit (week 30). An X-ray to determine BA and the measurement of anti-rhGH antibodies were performed both at screening and at week 26. BA was estimated using the Greulich-Pyle method by two independent pediatric endocrinologists who were blinded to the patients' demographics and assigned treatments. Blood samples for the pharmacokinetic (PK) and pharmacodynamic (PD) analyses of rhGH were taken at baseline from all patients. For patients randomized to the LB03002 groups, additional blood samples for $\mathrm{PK}$ and PD analyses were obtained at two time points, at $36 \mathrm{~h}$ and at 7 days after the last injection (26th dosing).

\section{Assessment of Study Endpoints}

The primary endpoint was the change in annualized height velocity (HV) at week 26 from baseline. $\mathrm{HV}$ was calculated using the following formula: $\mathrm{HV}(\mathrm{cm} /$ year $)$ = (last height measurement height at baseline) / (number of days between the first injection and last height measurement $) \times 365$. Standing height was measured three times using a calibrated stadiometer at each visit, and the mean values were used. To calculate the baseline HV, the baseline height and height measured at least 6 months before the baseline were used. The list of secondary endpoints included HV at week 13; height, IGF-I, IGF-I SDS, IGFBP-3, and IGFBP-3 SDS at week 13 and week 26; and height SDS for BA and chronological age (CA), BA, and $\triangle \mathrm{BA} / \triangle \mathrm{CA}$ at week 26 . The list of PK and PD parameters for LB03002 included the levels of human growth hormone (hGH), IGF-I, and IGFBP-3. Adverse events, injection site reactions, laboratory results, and anti-rhGH antibody level were considered as safety endpoints.

Assays

Serum levels of hGH, IGF-I, and IGFBP-3 were measured by chemiluminescence immunoassay using Immulite 2000 Immunoassay System (Siemens Healthcare Diagnostics Inc., Germany) at Seoul Medical Science Institute (SCL), South Korea, and anti-hGH antibodies were quantified using a radio-precipitation assay at the University of Leipzig, Germany. All assays have been validated for their limit of detection and quantification, precision, linearity, and recovery. Other laboratory parameters, such as functional parameters of the thyroid, complete blood count, blood chemistry, and urinalysis were determined at the SCL with an aid of validated assays.

\section{Statistical Analysis}

In order to select the optimal dose of LB03002, a noninferiority test for the change in $\mathrm{HV}$ at week 26 was carried out with the LB03002 groups against the daily rhGH group. Assuming a standard deviation (SD) of $1.7 \mathrm{~cm} /$ year for the change in $\mathrm{HV}$ and non- 
Table 1. Patient demographics at baseline (PPS)

\begin{tabular}{lccc}
\hline & $\begin{array}{l}\text { Daily rhGH } \\
0.37 \mathrm{mg} / \mathrm{kg} / \text { week } \\
(n=14)\end{array}$ & $\begin{array}{l}\text { LB03002 } \\
0.5 \mathrm{mg} / \mathrm{kg} / \mathrm{week} \\
(n=14)\end{array}$ & $\begin{array}{l}\text { LB03002 } \\
0.7 \mathrm{mg} / \mathrm{kg} / \mathrm{week} \\
(n=14)\end{array}$ \\
\hline Age, years & $5.86(1.29)$ & $5.36(1.22)$ & $6.07(1.54)$ \\
Male, $n$ & 10 & 9 & 10 \\
Female, $n$ & 6 & 5 & 6 \\
Birth weight, kg & $3.01(0.3)$ & $3.11(0.29)$ & $3.01(0.28)$ \\
Weight, kg & $17.46(2.42)$ & $16.61(2.43)$ & $18.94(6.84)$ \\
Mid-parental height, cm & $162.55(7.45)$ & $164.44(9.29)$ & $164.39(7.44)$ \\
Height, cm & $105.88(6.06)$ & $104.07(6.23)$ & $107.47(8.41)$ \\
Height SDS for CA & $-2.25(0.3)$ & $-2.28(0.29)$ & $-2.28(0.37)$ \\
Height SDS for CA $\leq-2.25, n$ & 5 & 8 & 6 \\
BA, years & $5.6(1.53)$ & $4.72(0.82)$ & $5.49(1.92)$ \\
Height SDS for BA & $-1.35(1.28)$ & $-0.69(1.32)$ & $-0.8(1.57)$ \\
Height velocity, cm/year & $6.24(1.6)$ & $6.11(1.3)$ & $5.51(0.94)$ \\
Peak GH plasma conc., ng/mL & $17.55(10,85.7)$ & $17.15(10.6,41)$ & $15.1(10.1,26.4)$ \\
IGF-I, ng/mL & $121(51.4,212)$ & $128(50.2,206)$ & $105(56.1,166)$ \\
IGF-I SDS & $-0.67(-1.39,0.39)$ & $-0.8(-2.03,0.63)$ & $-1.3(-2.06,0.15)$ \\
IGFBP-3, ng/mL & $3,660(2,200,4,980)$ & $3,490(2,450,5,910)$ & $3,655(2,440,5,040)$ \\
IGFBP-3 SDS & $2.2(-0.17,5.15)$ & $2.47(-0.11,8.9)$ & $1.89(0,5.27)$ \\
\hline
\end{tabular}

Continuous variables are presented with mean (SD) except peak GH plasma concentration, blood levels of IGF-I and IGFBP-3, and SDS of IGF-I and IGFBP-3, all of which are presented with median (min, max). Midparental height $(\mathrm{MPH})(\mathrm{cm})$ was calculated using the following formula: $\mathrm{MPH}$ (for boys) $=$ \{paternal height + $($ maternal height +13$)\} / 2 ; \mathrm{MPH}($ for girls $)=\{($ paternal height -13$)+$ maternal height $\} / 2$.

inferiority margin of $1.75 \mathrm{~cm} /$ year, 12 patients per group were considered sufficient to achieve $80 \%$ power to detect the betweengroup difference with a one-sided significance level of $5 \%$. The enrollment target was approximately 45 patients ( 15 per group) to accommodate $20 \%$ drop-out and protocol deviations. The primary endpoint was analyzed using the ANCOVA model with baseline HV covariates and treatment group, age ( $\geq 7$ or $<7$ years), and sex as fixed variables; two-sided $90 \%$ confidence interval (CI) for the least square (LS) mean difference was calculated, and if the lower bound of the CI was greater than -1.75 , noninferiority of LB03002 to daily rhGH was to be declared. The same ANCOVA model was used for the secondary endpoints. Missing values for the primary endpoint were replaced by the last available data according to the last-observation-carried-forward approach. For the computation of height SDS, the following equation was used referencing the power in the Box-Cox transformation (L), median (M), and coefficient of variation $(\mathrm{S})$ values from the growth standards for Korean children and adolescents [18]: height SDS = [power (measured height $/ \mathrm{M}, \mathrm{L})-1$ ] / L $\times$ S. The SDS for IGF-I and IGFBP-3 were computed using the following equation: SDS $=$ (measured value - mean population value) / SD of population value [19]. Treatment compliance was calculated by the following formula: (total number of vials used) / \{ (prescribed dose per injection $\times$ 26) / 1.2 f for LB03002 groups, and (total number of vials used) / $\{($ prescribed dose per injection $\times 6 \times 26) / 0.8\}$ for the comparator group. All treated patients who were randomized and received the study drug at least once were included in the safety analysis; treated patients with at least one height measurement after the baseline were included in the full analysis set (FAS), and patients without any major protocol deviations, such as treatment compliance $<80 \%$ or violation of eligibility criteria, were included in the perprotocol set (PPS), the main population for the efficacy evaluation. All statistical analyses were performed using SAS ${ }^{\circledR}$ software, version 9.2 (SAS Institute, Cary, NC, USA).

\section{Results}

\section{Patient Disposition and Characteristics}

From March 2014 to March 2015, 46 out of 51 screened patients were randomized and completed the study (Fig. 1). Except for 1 patient (daily rhGH group) whose treatment compliance was $79 \%$, all other patients reached more than $80 \%$ of treatment compliance. All randomized patients were included in the safety and FAS analyses. The PPS included 42 patients; another 4 patients were not included due to major protocol deviations, namely study drug compliance $<80 \%(n=1)$, dosage error $(n=2)$, and delay in initiation of the study treatment $(n=1)$. All patients were naïve to rhGH treatment, born at normal gestational ages (37-41 weeks), and presented with Tanner stage I. Mean height SDS for CA in all groups was less than -2 , with a 


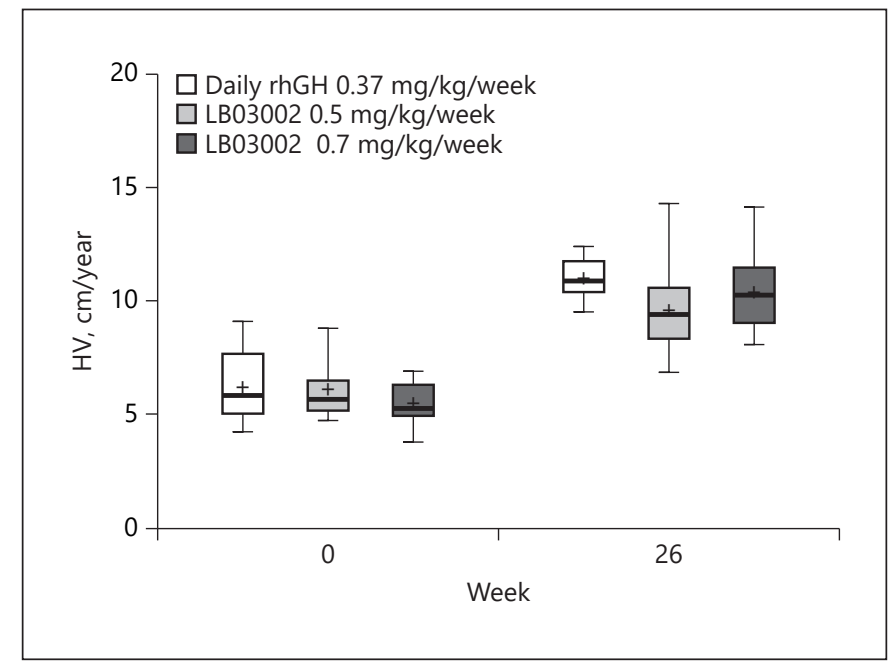

Fig. 2. Annualized height velocity (PPS). Before initiating rhGH treatment, median $\mathrm{HV}$ (cm/year) across three groups was less than $6 \mathrm{~cm} /$ year. A 6-month treatment resulted in significant increases in $\mathrm{HV}(p<0.001)$, with median changes ( $\mathrm{cm} /$ year) of $4.85,3.1$, and 4.69 in the daily rhGH, LB03002 $0.5 \mathrm{mg} / \mathrm{kg} /$ week, and LB03002 $0.7 \mathrm{mg} / \mathrm{kg} /$ week groups, respectively. The top and bottom of the box represent the 25th and 75th percentiles, the horizontal line inside the box represents the median, the symbol $(+)$ represents mean, and the whiskers represent 5 th and 95 th percentile.

range of -3.01 to -1.68 , and the proportion of extremely short patients (height SDS $\leq-2.25$ ) amounted to $45 \%$ (PPS). However, HV was mostly normal for the corresponding age group; $\mathrm{GH}$ secretion after the provocation test was normal $(\geq 10 \mathrm{ng} / \mathrm{mL})$ [17], and IGF-I and IGFBP-3 levels were within the reference ranges. The treatment groups were well balanced in terms of demographic and clinical characteristics (Table 1), yet the mean BA (years) of the LB03002 $0.5 \mathrm{mg} / \mathrm{kg} /$ week group was significantly lower than that of the daily rhGH group (4.72 vs. 5.93, $p=$ 0.041 ) in the FAS but not in the PPS ( 4.72 vs. $5.6, p=0.107)$.

\section{Efficacy Results}

At week 26, a significant increase in HV was documented in patients from all three groups (Fig. 2). No statistically significant difference in the actual mean $\mathrm{HV}$ change was found between each LB03002 dose group and the daily rhGH group (control). In the HV ANCOVA, the LS mean of the change in $\mathrm{HV}$ at week 26 in the control, LB03002 $0.5 \mathrm{mg} / \mathrm{kg} /$ week, and LB03002 $0.7 \mathrm{mg} / \mathrm{kg} /$ week group was 5.08, 3.65, and 4.38, respectively. The $90 \%$ CI for the LS mean of the change in $\mathrm{HV}$ versus control at week 26 was -2.43 to -0.44 and -1.72 to 0.33 for LB03002 $0.5 \mathrm{mg} / \mathrm{kg} /$ week and LB03002 $0.7 \mathrm{mg} / \mathrm{kg} /$ week, respective- ly. Thus, only the LB03002 $0.7 \mathrm{mg} / \mathrm{kg} /$ week group demonstrated noninferiority to control. Also, the FAS analysis yielded the same conclusion (lower bound of the $90 \%$ CI for the change in HV vs. control was -2.1 for LB03002 0.5 $\mathrm{mg} / \mathrm{kg} /$ week, and -1.21 for LB03002 $0.7 \mathrm{mg} / \mathrm{kg} /$ week). The ANCOVA interaction test showed that the change in $\mathrm{HV}$ was independent of the baseline HV, age, or sex. Consistent with the HV values, also height and height SDS for CA increased significantly in all three groups $(p<0.001)$, and the degree of changes at week 26 for LB03002 $0.7 \mathrm{mg} /$ $\mathrm{kg} /$ week group and control group were essentially similar (Table 2). The lower dose of LB03002 (0.5 mg/kg/week) consistently showed inferior response to the control at week 26 in terms of changes in height and height SDS in addition to the change in HV (see online suppl. Table 1; see www.karger.com/doi/10.1159/000489262 for all online suppl. material). While a post-treatment increase in BA was observed as well, it was not too advanced for CA, as indicated by the nonsignificant change in the $\mathrm{BA}$ advancement index $(\triangle \mathrm{BA} / \Delta \mathrm{CA})$ at week 26 . Irrespective of the treatment, the clinical changes mentioned above coexisted with an increase in pharmacodynamic parameters, IGF-I and IGFBP-3 (Table 2). However, a significant increase from baseline was observed solely in the controls and in the LB03002 $0.7 \mathrm{mg} / \mathrm{kg} /$ week group; these two groups did not differ significantly in terms of the degree of post-treatment change in IGF-I and IGFBP-3 levels.

\section{PK/PD Results}

Baseline blood concentrations of hGH in both LB03002 groups were similar, with individual values ranging from 0.05 to $18.5 \mathrm{ng} / \mathrm{mL}$. When blood samples were collected at $36 \mathrm{~h}$ after the 26th dosing, both groups showed a significant increase in the hGH level. This parameter increased in a dose-dependent manner, with a median (min, max) hGH level $(\mathrm{ng} / \mathrm{mL})$ equal to $15.15(1.16,38.8)$ and $40.55(7.42$, 83) for the $0.5 \mathrm{mg} / \mathrm{kg} /$ week and $0.7 \mathrm{mg} / \mathrm{kg} /$ week group, respectively $(p<0.001)$. At 7 days after the 26 th dosing, blood concentrations of hGH in nearly half of the patients were lower than $5 \mathrm{ng} / \mathrm{mL}$, and no significant between-group differences were found in hGH levels ( $p=0.467)$. Also, IGF-I and IGFBP- 3 concentrations at $36 \mathrm{~h}$ after the 26 th dosing were significantly higher than at the baseline $(p<0.001)$, without statistically significant between-group differences in either parameter (see online suppl. Table 2).

\section{Safety Results}

During the 30-week study period, 7 (44\%), 9 (64\%), and $10(63 \%)$ patients from the control, LB03002 $0.5 \mathrm{mg} /$ $\mathrm{kg} /$ week, and LB03002 $0.7 \mathrm{mg} / \mathrm{kg} /$ week groups experi-
58

Horm Res Paediatr 2018;90:54-63 DOI: $10.1159 / 000489262$
Hwang/Lee/Lee/Yoo/Lee/Suh/Ko/Chung/ Jin/Shin/Han/Han/Kim 
Table 2. Changes from baseline in efficacy endpoints (PPS)

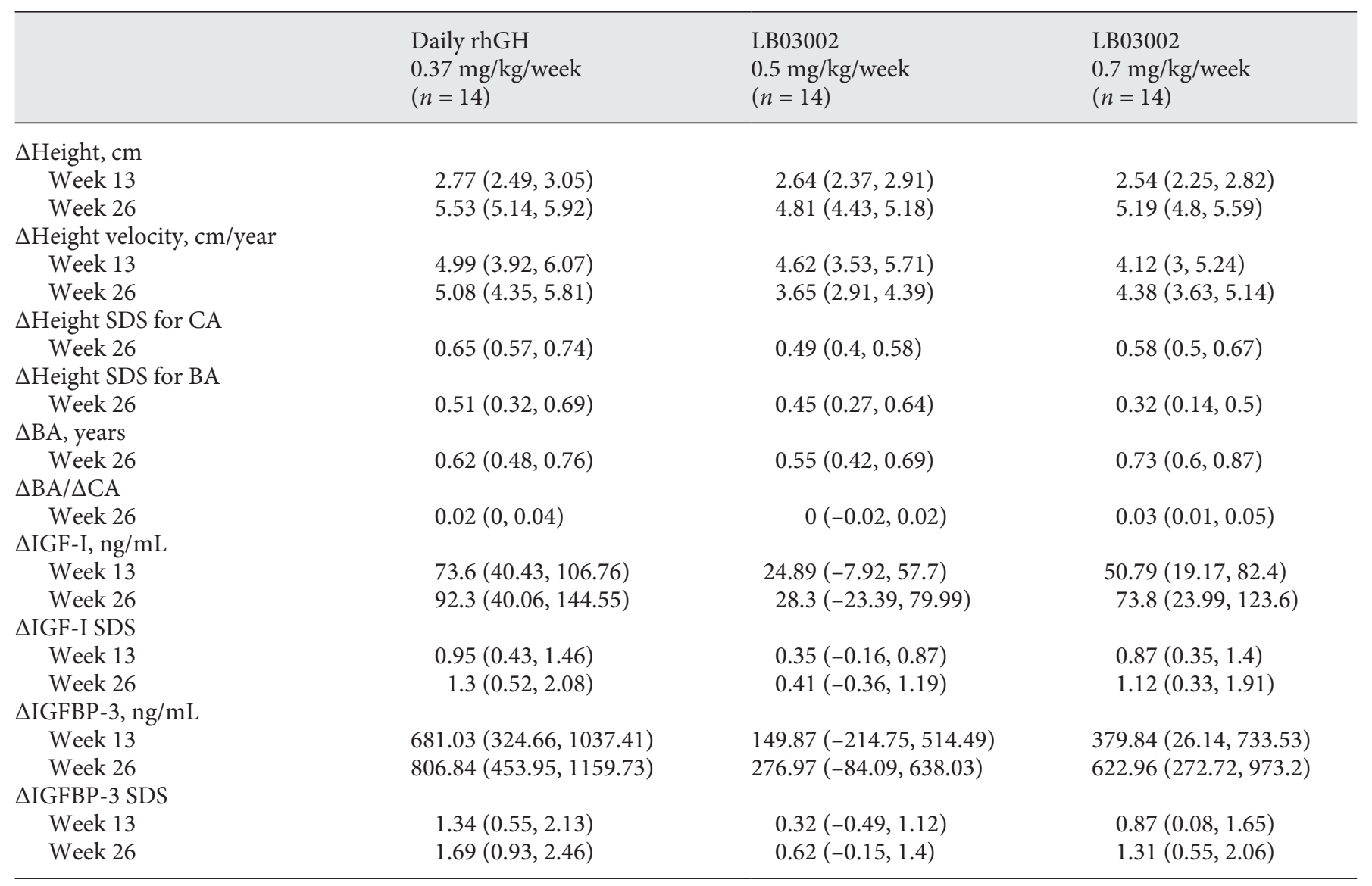

Data are changes from baseline at each time point, presented as LS mean (90\% CI).

enced 12, 28, and 23 adverse events, respectively (Table $3)$. The adverse events were mostly mild except 1 severe and 3 moderate events reported in the LB03002 $0.5 \mathrm{mg} /$ $\mathrm{kg} /$ week group. Eight adverse events were related with the rhGH treatment, mostly with LB03002 $0.5 \mathrm{mg} / \mathrm{kg} /$ week $(n=7)$ and LB03002 $0.7 \mathrm{mg} / \mathrm{kg} /$ week $(n=1)$ : injection site pruritus $(n=1)$, acute tonsillitis $(n=1)$, bronchitis $(n=$ $2)$, acute otitis media $(n=1)$, upper respiratory tract infection $(n=1)$, atopic dermatitis $(n=1)$, and rash $(n=1)$ as preferred terms. Two serious adverse events (meningitis and thermal burn) were reported with LB03002 0.5 $\mathrm{mg} / \mathrm{kg} /$ week; however, neither had any causal relationship with the treatment.

Regarding injection site reactions (warmth, erythema, and swelling), swelling occurred most frequently, and the patients receiving LB03002 experienced local reactions more frequently than those administered daily rhGH (Table 4). However, the intensity was generally tolerable, and the reactions were mostly resolved within 6 days (Ta-

Use of Weekly GH in Idiopathic Short Stature ble 4). The severity of pain, marked on the $150-\mathrm{mm}$ visual analogue scale (VAS), did not exceed half of the VAS length and showed a decreasing tendency with repeated injections.

When looking at the individual subject's IGF-I SDS, 10 and 11 subjects in the LB03002 $0.5 \mathrm{mg} / \mathrm{kg} /$ week and LB03002 $0.7 \mathrm{mg} / \mathrm{kg} /$ week group, respectively, had IGF-I greater than 2 SDS at $36 \mathrm{~h}$ after the last injection. However, the nonphysiological level of IGF-I was mostly normalized at 7 days after the last injection (see online suppl. Fig. 1). No laboratory abnormalities were assessed to be clinically relevant. None of the patients tested positive for anti-hGH antibodies at the baseline, whereas at week 26, anti-hGH antibodies were detected in 3 and 6 patients from the LB03002 $0.5 \mathrm{mg} / \mathrm{kg} /$ week and $0.7 \mathrm{mg} / \mathrm{kg} /$ week group, respectively. The subgroup analysis demonstrated that the presence of anti-hGH antibodies did not affect the change in $\mathrm{HV}$ at week 26 or blood hGH concentration at $36 \mathrm{~h}$ after the 26th dosing (data not shown).

Horm Res Paediatr 2018;90:54-63 
Table 3. List of adverse events

\begin{tabular}{|c|c|c|c|}
\hline Preferred term & $\begin{array}{l}\text { Daily rhGH } \\
0.37 \mathrm{mg} / \mathrm{kg} / \text { week } \\
(n=16)\end{array}$ & $\begin{array}{l}\text { LB03002 } \\
0.5 \mathrm{mg} / \mathrm{kg} / \text { week } \\
(n=14)\end{array}$ & $\begin{array}{l}\text { LB03002 } \\
0.7 \mathrm{mg} / \mathrm{kg} / \text { week } \\
(n=16)\end{array}$ \\
\hline Ear pain & $0(0)$ & $1(1)$ & $0(0)$ \\
\hline Dyspepsia & $0(0)$ & $0(0)$ & $1(1)$ \\
\hline Enteritis & $0(0)$ & $1(1)$ & $2(2)$ \\
\hline Vomiting & $0(0)$ & $1(1)$ & $0(0)$ \\
\hline Injection site pruritus & $0(0)$ & $1(1)$ & $1(1)$ \\
\hline Acute tonsillitis & $0(0)$ & $1(1)$ & $1(2)$ \\
\hline Bronchitis & $0(0)$ & $2(4)$ & $0(0)$ \\
\hline Folliculitis & $0(0)$ & $1(1)$ & $0(0)$ \\
\hline Furuncle & $1(1)$ & $0(0)$ & $0(0)$ \\
\hline Hordeolum & $1(1)$ & $0(0)$ & $1(1)$ \\
\hline Laryngitis & $1(1)$ & $0(0)$ & $0(0)$ \\
\hline Meningitis & $0(0)$ & $1(1)^{\mathrm{a}}$ & $0(0)$ \\
\hline Nasopharyngitis & $3(3)$ & $1(2)$ & $2(5)$ \\
\hline Otitis externa & $0(0)$ & $0(0)$ & $1(1)$ \\
\hline Acute otitis media & $0(0)$ & $1(1)$ & $0(0)$ \\
\hline Pharyngitis & $1(1)$ & $2(2)$ & $0(0)$ \\
\hline Tonsillitis & $1(1)$ & $1(1)$ & $0(0)$ \\
\hline Tracheitis & $0(0)$ & $0(0)$ & $1(1)$ \\
\hline Upper respiratory tract infection & $1(1)$ & $3(6)$ & $1(2)$ \\
\hline Varicella & $0(0)$ & $0(0)$ & $1(1)$ \\
\hline Foot fracture & $1(1)$ & $0(0)$ & $0(0)$ \\
\hline Laceration & $0(0)$ & $1(1)^{\mathrm{a}}$ & $0(0)$ \\
\hline Thermal burn & $0(0)$ & $1(1)^{b}$ & $0(0)$ \\
\hline Arthralgia & $0(0)$ & $0(0)$ & $1(1)$ \\
\hline Headache & $0(0)$ & $0(0)$ & $1(4)$ \\
\hline Balanoposthitis & $0(0)$ & $1(1)$ & $0(0)$ \\
\hline Allergic rhinitis & $1(1)$ & $0(0)$ & $0(0)$ \\
\hline Atopic dermatitis & $0(0)$ & $1(1)^{\mathrm{a}}$ & $1(1)$ \\
\hline Rash & $1(1)$ & $1(1)$ & $0(0)$ \\
\hline
\end{tabular}

Numbers before parentheses represent the number of patients experiencing each adverse event, whereas those in the parentheses represent the total number of each event. ${ }^{a}$ Moderate in intensity. ${ }^{b}$ Severe in intensity; the rest of the events were mild in intensity.

\section{Discussion}

In this open-label, randomized study targeting Korean children diagnosed with ISS, LB03002 $0.7 \mathrm{mg} / \mathrm{kg} /$ week was noninferior to daily rhGH administered 6 times per week at the total dose of $0.37 \mathrm{mg} / \mathrm{kg} /$ week. Both products were well tolerated without significant adverse reactions.

Despite the use of thin needles and alternative delivery routes, daily administration of rhGH may be inconvenient. Owing to the long duration of the therapy, this may negatively affect patient's or caregiver's adherence to the treatment schedules. Indeed, one previous study demonstrated a significant difference in the mean treatment duration between good compliance and moderate-poor compliance groups (2.78 vs. 3.78 years, $p=0.001)$ [20].
Moreover, available evidence shows that poor adherence to the rhGH regimen is quite frequent and may negatively affect the treatment outcome [21-24]. Even though there is no evidence to prove a better adherence with longacting rhGH than with daily rhGH, reducing the dosing frequency to once a week, theoretically, can be considered a benefit to patients and their caregivers, if proved to be at least as safe and effective as daily rhGH. Based on this premise, we conducted a randomized study in children with ISS to select the optimal dose of LB03002; the safety and efficacy of this agent, administered at 0.5 or $0.7 \mathrm{mg} /$ $\mathrm{kg} /$ week, were compared with respective characteristics of daily rhGH given at a labeled dose for ISS patients $(0.37$ $\mathrm{mg} / \mathrm{kg} /$ week). The first dosage regimen of LB03002 (0.5 $\mathrm{mg} / \mathrm{kg} /$ week) is the recommended dose of this product for
60

Horm Res Paediatr 2018;90:54-63 DOI: $10.1159 / 000489262$
Hwang/Lee/Lee/Yoo/Lee/Suh/Ko/Chung/ Jin/Shin/Han/Han/Kim 
Table 4. Number of patients with injection site reactions by maximal intensity

\begin{tabular}{|c|c|c|c|}
\hline & $\begin{array}{l}\text { Daily rhGH } \\
0.37 \mathrm{mg} / \mathrm{kg} / \text { week } \\
(n=16)\end{array}$ & $\begin{array}{l}\text { LB03002 } \\
0.5 \mathrm{mg} / \mathrm{kg} / \text { week } \\
(n=14)\end{array}$ & $\begin{array}{l}\text { LB03002 } \\
0.7 \mathrm{mg} / \mathrm{kg} / \text { week } \\
(n=16)\end{array}$ \\
\hline \multicolumn{4}{|l|}{ Maximum intensity } \\
\hline \multicolumn{4}{|l|}{ Warmth } \\
\hline None & 12 & 5 & 5 \\
\hline Mild & 4 & 8 & 9 \\
\hline Moderate & 0 & 1 & 2 \\
\hline \multicolumn{4}{|l|}{ Erythema } \\
\hline None & 12 & 2 & 1 \\
\hline Mild (<5 mm) & 3 & 5 & 4 \\
\hline Moderate $(\geq 5 \mathrm{~mm},<20 \mathrm{~mm})$ & 0 & 5 & 7 \\
\hline Severe $(\geq 20 \mathrm{~mm})$ & 1 & 2 & 4 \\
\hline \multicolumn{4}{|l|}{ Swelling } \\
\hline None & 9 & 1 & 0 \\
\hline Mild (<3 mm) & 6 & 2 & 4 \\
\hline Moderate $(\geq 3 \mathrm{~mm},<20 \mathrm{~mm})$ & 1 & 6 & 5 \\
\hline Severe $(\geq 20 \mathrm{~mm})$ & 0 & 5 & 7 \\
\hline \multicolumn{4}{|l|}{ Duration (after 1st dosing) } \\
\hline \multicolumn{4}{|l|}{ Warmth } \\
\hline $0 \sim 3$ day & 2 & 4 & 4 \\
\hline $4 \sim 6$ day & 1 & 1 & 1 \\
\hline Over 7 day & 0 & 0 & 0 \\
\hline \multicolumn{4}{|l|}{ Erythema } \\
\hline $0 \sim 3$ day & 1 & 5 & 6 \\
\hline $4 \sim 6$ day & 1 & 3 & 5 \\
\hline Over 7 day & 1 & 0 & 0 \\
\hline \multicolumn{4}{|l|}{ Swelling } \\
\hline $0 \sim 3$ day & 1 & 5 & 10 \\
\hline $4 \sim 6$ day & 1 & 6 & 3 \\
\hline Over 7 day & 0 & 0 & 0 \\
\hline
\end{tabular}

pediatric GHD patients. For the second regimen, a higher dosage $(0.7 \mathrm{mg} / \mathrm{kg} /$ week $)$ than the one approved for GHD was to be tested based on the evidence that ISS patients show worse growth response to rhGH therapy than patients with severe GHD [10]. High-dose rhGH therapy $(0.7 \mathrm{mg} / \mathrm{kg} /$ week, daily) had previously been demonstrated to be effective and safe in GH-deficient adolescents who were most growth-retarded at the onset of puberty [25]. Finally, the PK/PD profiles of LB03002 administered at either 0.5 or $0.7 \mathrm{mg} / \mathrm{kg} /$ week were shown to be suitable for a long-term treatment of children with GHD $[16,26]$. Although the PK/PD profiles of LB03002 in children with ISS were out of the scope of the present study, sparse data on the dynamics of hGH, IGF-I, and IGFBP-3 levels imply that they may be similar to those documented previously in GHD patients. The increase in hGH, IGF-I, and IGFBP-3 observed at $36 \mathrm{~h}$ after the last dose may imply that the patients were adequately exposed to LB03002, though a physiologically high level of IGF-I may be of concern. Further, the return of hGH, IGF-I, and IGFBP-3 to their baseline levels at 7 days after the last dose may suggest that repeated administration of LB03002 did not result in accumulation thereof.

In terms of the primary efficacy evaluation, administration of either LB03002 (irrespective of the dose) or the comparator resulted in a significant increase in HV in ISS patients $(p<0.0001)$. The changes in HV documented in all three groups $(3.65-5.08 \mathrm{~cm} /$ year) were comparable with the assumed effect size $(3.99 \mathrm{~cm} /$ year $)$ and the 1-year change observed in other studies $[8,27,28]$. Also, the 
height SDS gain (LS mean ranging from 0.49 to 0.65 ) observed during the 26-week study period was within the expected range, owing a 0-0.7 SDS gain over 1 year documented in a systematic review analyzing the effects of rhGH on short-term growth in children with ISS [4]. However, LB03002, administered at $0.5 \mathrm{mg} / \mathrm{kg} /$ week, failed to prove noninferiority to the control in terms of the HV change. The first plausible explanation is that the LB03002 dose $(0.5 \mathrm{mg} / \mathrm{kg} /$ week $)$ might not have been high enough to improve the HV of children with ISS. In the previous phase III trial of Korean GHD patients [15], HV achieved after administration of LB03002 at $0.5 \mathrm{mg} /$ $\mathrm{kg} /$ week was not inferior to that obtained with daily $\mathrm{rhGH}$ $0.21 \mathrm{mg} / \mathrm{kg} /$ week. This implies that a higher dose $(0.7 \mathrm{mg} /$ $\mathrm{kg} /$ week) of LB03002 should be considered for children with ISS. The other potential explanation is that the number of patients per group was too small to balance individual variability inherent to the heterogenous genetic makeup of the ISS population [29].

Overall, the adverse event rate was higher in the LB03002 groups than in the controls; however, the frequency of adverse drug reactions (ADRs) was low (4 patients in the LB03002 groups had a total of 8 ADRs), and most ADRs (7/8) were classified as mild. Also, injection site reactions were more common in the LB03002 groups, but usually resolved within 3-6 days since the onset, and the injection site pain caused by LB03002 waned within 2-3 days. The severity of pain in all three groups tended to decrease with repeated dosing, which implies that the patients tolerated well either the daily or the weekly regimen. Moreover, high treatment compliance $(\geq 80 \%)$ across all three groups suggests that the intensity of local reactions, among them pain, was not clinically significant and did not prevent the patients from following the treatment regimen. Therefore, the safety profiles of LB03002 at both doses administered to children with ISS for 26 weeks were assessed to be acceptable and comparable with that of the control. Meanwhile, favorable long-term (2-3 years) safety data of LB03002 can be referenced both from the phase II/III [26] and phase III [16] studies conducted in GHD children.

Some cautions should be taken while interpreting the results of this study. First, the annualized HV data were based on the height measurements taken at 6-month intervals. Considering the potential seasonal variance of individual growth, the 1-year period would be ideal; however, 6 months were considered to be a minimum necessary period for this type of study. Second, the safety profile of LB03002 in ISS patients was determined on the basis of a relatively short follow-up; thus, the safety of this agent needs to be verified in a longer time perspective, considering that rhGH treatment is typically administered for several years. Third, it should be remembered that diagnostic criteria for ISS vary from country to country; some authors recommend more stringent cutoff values for height SDS than those applied in this study (height SDS $<-2.25$ or even $<-3.0$ ) [30]. Finally, prescription of rhGH to otherwise healthy children, such as ISS patients, should be preceded by a systematic and critical evaluation of multiple factors, e.g., social well-being, functional impact, and economic burden, rather than solely a height gain $[31,32]$. All these factors need to be considered in future studies of LB03002.

In conclusion, the once-weekly regimen of LB03002 $0.7 \mathrm{mg} / \mathrm{kg}$ demonstrated noninferiority to the daily-divided regimen of rhGH $0.37 \mathrm{mg} / \mathrm{kg} /$ week in terms of $\mathrm{HV}$ increments. A 26-week treatment contributed to a significant increase in auxological variables (HV, height gain, and height SDS) and concomitant changes in PD markers. Both doses of LB03002 were well tolerated and their safety profiles were comparable with that of daily rhGH. A confirmatory efficacy study needs to be undertaken with LB03002 $0.7 \mathrm{mg} / \mathrm{kg} /$ week in children with ISS.

\section{Acknowledgement}

We thank the patients and their caregivers; Suin Lee of LG Chem, Ltd., for her support in clinical operations; and Hye-Ryon Kim and Szymon Brużewicz (SciencePro) for editorial assistance in the preparation of the manuscript.

\section{Disclosure Statement}

This study was sponsored by LG Life Sciences, Ltd., which is now merged with LG Chem, Ltd., Korea. S.H. is employed by LG Chem, Ltd. J.S.H., K.-H.L., H.-W.Y., B.-K.S., C.H.S., H.-S.H., H.-S.K., and C.H.S. are the Steering Committee members of LGS (LG Growth Study). Otherwise, the authors have no competing interest to declare that could be perceived as prejudicing the impartiality of the research reported.

\section{References}

62
Horm Res Paediatr 2018;90:54-63 DOI: $10.1159 / 000489262$
1 Lindsay R, Feldkamp M, Harris D, Robertson J, Rallison M. Utah Growth Study: growth standards and the prevalence of growth hormone deficiency. J Pediatr. 1994 Jul;125(1): 29-35.

2 Voss LD, Mulligan J, Betts PR, Wilkin TJ. Poor growth in school entrants as an index of organic disease: the Wessex growth study. BMJ. 1992 Dec;305(6866):1400-2.
62 DOI. $10.1159 / 000489262$
Hwang/Lee/Lee/Yoo/Lee/Suh/Ko/Chung/ Jin/Shin/Han/Han/Kim 
3 Wit JM, Clayton PE, Rogol AD, Savage MO, Saenger PH, Cohen P. Idiopathic short stature: definition, epidemiology, and diagnostic evaluation. Growth Horm IGF Res. 2008 Apr; 18(2):89-110.

4 Bryant J, Baxter L, Cave CB, Milne R. Recombinant growth hormone for idiopathic short stature in children and adolescents. Cochrane Database Syst Rev. 2007 Jul;(3):CD004440.

5 Ranke MB. Towards a consensus on the definition of idiopathic short stature. Horm Res. 1996;45 Suppl 2:64-6.

6 Şıklar Z, Kocaay P, Çamtosun E, İsakoca M, Hacıhamdioğlu B, Savaş Erdeve Ş et al. The Effect of Recombinant Growth Hormone Treatment in Children with Idiopathic Short Stature and Low Insulin-Like Growth Factor-1 Levels. J Clin Res Pediatr Endocrinol. 2015 Dec;7(4):301-6.

7 Leschek EW, Rose SR, Yanovski JA, Troendle JF, Quigley CA, Chipman JJ et al; National Institute of Child Health and Human Development-Eli Lilly \& Co. Growth Hormone Collaborative Group. Effect of growth hormone treatment on adult height in peripubertal children with idiopathic short stature: a randomized, double-blind, placebo-controlled trial. J Clin Endocrinol Metab. 2004 Jul;89(7): 3140-8.

8 Kemp SF, Kuntze J, Attie KM, Maneatis T, Butler S, Frane J et al. Efficacy and safety results of long-term growth hormone treatment of idiopathic short stature. J Clin Endocrinol Metab. 2005 Sep;90(9):5247-53.

9 Cohen P, Rogol AD, Weng W, Kappelgaard AM, Rosenfeld RG, Germak J; American Norditropin Study Group. Efficacy of IGF-based growth hormone $(\mathrm{GH})$ dosing in nonGH-deficient (nonGHD) short stature children with low IGF-I is not related to basal IGF-I levels. Clin Endocrinol (Oxf). 2013 Mar;78(3): 405-14.

10 Cohen P, Germak J, Rogol AD, Weng W, Kappelgaard AM, Rosenfeld RG; American Norditropin Study Group. Variable degree of growth hormone $(\mathrm{GH})$ and insulin-like growth factor (IGF) sensitivity in children with idiopathic short stature compared with GH-deficient patients: evidence from an IGFbased dosing study of short children. J Clin Endocrinol Metab. 2010 May;95(5):2089-98.

11 Albertsson-Wikland K, Aronson AS, Gustafsson J, Hagenäs L, Ivarsson SA, Jonsson B et al. Dose-dependent effect of growth hormone on final height in children with short stature without growth hormone deficiency. J Clin Endocrinol Metab. 2008 Nov;93(11):434250.

12 Saenger PH, Mejia-Corletto J. Long-Acting Growth Hormone: an Update. Endocr Dev. 2016;30:79-97.
13 Kim SJ, Kim CW. Development and Charac terization of Sodium Hyaluronate Microparticle-Based Sustained Release Formulation of Recombinant Human Growth Hormone Prepared by Spray-Drying. J Pharm Sci. 2016 Feb;105(2):613-22.

14 Biller BM, Ji HJ, Ahn H, Savoy C, Siepl EC, Popovic V et al. Effects of once-weekly sustained-release growth hormone: a doubleblind, placebo-controlled study in adult growth hormone deficiency. J Clin Endocrinol Metab. 2011 Jun;96(6):1718-26.

15 Hwang JS, Lee HS, Chung WY, Han HS, Jin DK, Kim HS et al. Efficacy and safety of LB03002, a once-weekly sustained-release human GH for 12-month treatment in Korean children with GH deficiency. Eur J Endocrinol. 2013 Jul;169(2):179-85.

16 Khadilkar V, Radjuk KA, Bolshova E, Khadgawat R, El Kholy M, Desai M et al. 24-month use of once-weekly GH, LB03002, in prepubertal children with GH deficiency. J Clin Endocrinol Metab. 2014 Jan;99(1):126-32.

17 Cohen P, Rogol AD, Deal CL, Saenger P, Reiter EO, Ross JL et al; 2007 ISS Consensus Workshop participants. Consensus statement on the diagnosis and treatment of children with idiopathic short stature: a summary of the Growth Hormone Research Society, the Lawson Wilkins Pediatric Endocrine Society, and the European Society for Paediatric Endocrinology Workshop. J Clin Endocrinol Metab. 2008 Nov;93(11):4210-7.

18 Korea Center for Disease Control and Prevention. The Korean Pediatric Society, The Committee for the Development of Growth Standard for Korean Children and Adolescents: Korean children and adolescents growth standard (commentary for the development of 2007 growth chart) [cited $2015 \mathrm{Apr}$ 8]. Available from: http://www.cdc.go.kr/ $\mathrm{CDC} / \mathrm{cms} / \mathrm{cmsFileDownload}$.jsp?fid=28\&am p;cid $=1235 \&$ amp;fieldName $=$ attachGrp\&am p;index $=4$.

19 Hyun SE, Lee BC, Suh BK, Chung SC, Ko CW, Kim HS et al. Reference values for serum levels of insulin-like growth factor-I and insulinlike growth factor binding protein-3 in Korean children and adolescents. Clin Biochem. 2012 Jan;45(1-2):16-21.

20 De Pedro S, Murillo M, Salinas I, Granada $\mathrm{ML}$, Martinez $\mathrm{M}$, Puig-Domingo $\mathrm{M}$ et al. Variability in adherence to rhGH treatment: socioeconomic causes and effect on children's growth. Growth Horm IGF Res. 2016 Feb;26: 32-5.

21 Lanes R. Long-term outcome of growth hormone therapy in children and adolescents. Treat Endocrinol. 2004;3(1):53-66.
22 Cutfield WS, Derraik JG, Gunn AJ, Reid K, Delany T, Robinson E et al. Non-compliance with growth hormone treatment in children is common and impairs linear growth. PLoS One. 2011 Jan;6(1):e16223.

23 Kapoor RR, Burke SA, Sparrow SE, Hughes IA, Dunger DB, Ong KK et al. Monitoring of concordance in growth hormone therapy. Arch Dis Child. 2008 Feb;93(2):147-8.

24 Desrosiers P, O’Brien F, Blethen S. Patient outcomes in the GHMonitor: the effect of delivery device on compliance and growth. Pediatr Endocrinol Rev. 2005 Feb;2 Suppl 3: $327-31$

25 Mauras N, Attie KM, Reiter EO, Saenger P, Baptista J. High dose recombinant human growth hormone $(\mathrm{GH})$ treatment of $\mathrm{GH}$-deficient patients in puberty increases near-final height: a randomized, multicenter trial. Genentech, Inc., Cooperative Study Group. J Clin Endocrinol Metab. 2000 Oct;85(10): 3653-60

26 Péter F, Bidlingmaier M, Savoy C, Ji HJ, Saenger PH. Three-year efficacy and safety of LB03002, a once-weekly sustained-release growth hormone $(\mathrm{GH})$ preparation, in prepubertal children with GH deficiency (GHD). J Clin Endocrinol Metab. 2012 Feb;97(2): $400-7$.

27 Genentech Collaborative Study Group. Idiopathic short stature: results of a one-year controlled study of human growth hormone treatment. J Pediatr. 1989 Nov;115(5 Pt 1): 713-9.

28 Soliman AT, Abdul Khadir MM. Growth parameters and predictors of growth in short children with and without growth hormone (GH) deficiency treated with human GH: a randomized controlled study. J Trop Pediatr. 1996 Oct;42(5):281-6.

29 Dauber A, Rosenfeld RG, Hirschhorn JN. Genetic evaluation of short stature. J Clin Endocrinol Metab. 2014 Sep;99(9):3080-92.

30 Grimberg A, DiVall SA, Polychronakos C, Allen DB, Cohen LE, Quintos JB et al; Drug and Therapeutics Committee and Ethics Committee of the Pediatric Endocrine Society. Guidelines for Growth Hormone and InsulinLike Growth Factor-I Treatment in Children and Adolescents: Growth Hormone Deficiency, Idiopathic Short Stature, and Primary Insulin-Like Growth Factor-I Deficiency. Horm Res Paediatr. 2016;86(6):361-97.

31 Allen DB. Growth Promotion Ethics and the Challenge to Resist Cosmetic Endocrinology. Horm Res Paediatr. 2017;87(3):145-52.

32 Arnhold IJ, Sandberg DE. Additional Considerations to the Ethics of Growth Promotion and Challenges to Human Growth Hormone (hGH)-for-Height Therapy. Horm Res Paediatr. 2017;88(3-4):305-6. 